\title{
QUALIDADE FISIOLÓGICA DE SEMENTES DE BETERRABA (Beta vulgaris L.) SOB CONDICIONAMENTO OSMÓTICO E TRATAMENTOS FUNGICIDAS ${ }^{1}$
}

\author{
MARISTELA APARECIDA DIAS ${ }^{2}$, LEONARDO A. AQUINO ${ }^{3}$, DENISE C. F.S. DIAS ${ }^{4}$, EVELINE M. ALVARENGA4.
}

\begin{abstract}
RESUMO - O condicionamento osmótico e o tratamento de sementes com fungicidas têm apresentado bons resultados na melhoria do vigor e proteção das plântulas contra patógenos associados às sementes e de solo, garantindo assim bom estabelecimento do estande. Objetivou-se com este trabalho, avaliar o efeito do condicionamento osmótico e do tratamento com fungicidas sobre a qualidade fisiológica de sementes de beterraba (Beta vulgaris L.). As sementes foram condicionadas em água, $\mathrm{KNO}^{3}(0,34$ M) e PEG 6000 (-0,8 MPa). Os tratamentos com fungicidas foram: testemunha (sementes tratadas pela empresa produtora de sementes com Thiran a $0,15 \%)$, metalaxil $(0,004 \%)$, procimidone $(0,1 \%) \mathrm{e}$ metalaxil + procimidone $(0,004+0,1 \%)$. Avaliaram-se as seguintes características: primeira contagem, contagem no oitavo dia e final pelo teste de germinação; emergência, velocidade de emergência e índice de velocidade de emergência em substrato comercial e em solo. Adotou-se o delineamento inteiramente casualizado, esquema fatorial (condicionamento x tratamento com fungicidas), com quatro repetições, realizando-se a comparação de médias pelo teste Duncan a 5\% de probabilidade. O condicionamento das sementes em água por $16 \mathrm{~h}$, associado com o tratamento com o fungicida Metalaxil $(0,004 \%)$, proporciona melhores resultados no teste de germinação e no estabelecimento de plântulas em solo.
\end{abstract}

Termos para indexação: Beta vulgaris var crassa; priming; damping off; emergência em solo.

\section{PHYSIOLOGICAL QUALITY OF SUGAR BEET (Beta vulgaris L.) SEEDS UNDER OSMOTIC CONDITIONING AND TREATMENTS WITH FUNGICIDE}

\begin{abstract}
The osmotic conditioning and fungicide treatments of seeds have presented good results in vigor improvement and seedling protection against microorganisms associated to the seeds and soil, thus guaranteeing good stand establishment. The objective of this study was to evaluate the effect of osmotic conditioning and fungicide treatment on the physiological quality of beet seeds. The seeds were conditioned in water, $\mathrm{KNO}^{3}$ (0.34 M), PEG 6000 (-0.8 MPa). The treatments with fungicides were: control (seeds treated by the seed producing Company with Thiran to $0,15 \%)$, metalaxil $(0,004 \%)$, procimidone $(0,1 \%)$ and metalaxil + procimidone $(0,004+0,1 \%)$. The following characteristics were evaluated: first count, count on the eighth day and final day for the germination test; emergence, emergence speed and index of emergence speed in commercial substratum and soil. A randomized complete design was used, factorial arragement (conditioning $\mathrm{x}$
\end{abstract}

${ }^{1}$ Submetido em 13/11/2007. Aceito para publicação em 07/06/2008.

${ }^{2}$ Eng. Agr., M.Sc. Estudante de Doutorado em Fitotecnia, UFV, ViçosaMG, CEP 36570-000. E-mail: dias-maristela@hotmail.com

${ }^{3}$ Eng. Agr., M.Sc., Estudante de Doutorado em Fitotecnia,
UFV; Prof. do CEFET Januária, Januária-MG, CEP 39480-000. E-mail: aquinoufv@yahoo.com.br;

${ }^{4}$ Prof. Associado do Depto de Fitotecnia da UFV -Viçosa-MG 
treatment with fungicides), with four replications, and the means were compared by the Duncan test at $5 \%$ probability. Conditioning of the seeds in water for $16 \mathrm{~h}$, associated with the treatment with the fungicide Metalaxil fungicide $(0.004 \%)$ presented the best results in the germination test and in the seedling establishment in soil.

Index terms: Beta vulgaris var crassa; priming; damping off; emergence in soil.

\section{INTRODUÇÃO}

A qualidade de sementes é vista como a capacidade destas apresentarem bom desempenho no campo, com altos níveis de germinação, sob as mais variadas condições, originando plantas vigorosas e potencialmente produtivas, no menor tempo possível (Carvalho e Nakagawa, 2000). A utilização de sementes com alta germinação e vigor representa uma garantia aos produtores, que terão maior probabilidade de êxito no estabelecimento do estande adequado na lavoura. $\mathrm{Na}$ produção olerícola este fato se reveste de grande importância devido ao alto custo das sementes das novas cultivares existentes no mercado (Nascimento, 2005).

Pertencente à família Chenopodiaceae, a beterraba é originária das regiões Mediterrânea e do Norte da África. No Brasil, as Regiões Sudeste e Sul cultivam $77 \%$ do que é produzido. As sementes desta espécie são, na verdade, aglomerados de três a quatro pequenos frutos corticosos, formando glomérulos. Na cultura da beterraba, um dos fatores limitantes à produtividade da cultura está associado à germinação baixa ou irregular em campo (Puiatti e Finger, 2005; Silva e Vieira, 2006).

A desuniformidade a germinação também decorre de condições de campo inadequadas, constituindo um dos principais problemas para as diversas espécies hortícolas. Uma das técnicas recomendadas para uniformizar a germinação e emergência em campo é o condicionamento osmótico ou "priming", que constitui no pré-tratamento no qual as sementes são imersas em solução osmótica sob tempo e temperatura determinados, de modo a restringir a quantidade de água absorvida. Assim, ocorrem as fases iniciais da germinação (fase I e II), sem atingir o estádio de emergência da radícula (fase III), segundo o padrão trifásico descrito por Bewley e Black (1994). Após condicionadas, as sementes podem ser submetidas à secagem, que visa interromper os processos metabólicos dos quais resultaria a protrusão da raiz primária. Sementes condicionadas, ao serem expostas às condições favoráveis à germinação, esta ocorreria de maneira mais rápida e uniforme (Tonin et al., 2005). A técnica do condicionamento osmótico tem sido utilizada principalmente para espécies olerícolas e ornamentais, nas quais o prolongamento do período transcorrido desde a semeadura até a emergência das plântulas pode comprometer a produtividade e a qualidade da produção (Costa e Villela, 2006; Nascimento, 2004).

Agentes osmóticos inorgânicos como $\mathrm{KNO}_{3}$ e orgânicos como polietilenoglicol (PEG) por serem osmoticamente ativos, reduzem o potencial hídrico da solução de embebição das sementes, permitindo o controle do nível de embebição das mesmas. O PEG com alto peso molecular (6000 ou 8000) é um dos agentes osmóticos mais utilizados, uma vez que produz uma solução caracterizada como inerte, estável e sem efeitos tóxicos (Haigh et al., 1986; Nascimento, 2004). Khan et al. (1983) trabalhando com sementes de beterraba verificaram que o condicionamento com o PEG foi uma técnica eficiente para elevar o número de plântulas obtidas 20 dias após a semeadura. Também Yeoung e Wilson (1995) obtiveram 10\% de incremento na taxa de germinação de sementes de beterraba açucareira osmoticamente condicionadas em solução de PEG.

$\mathrm{O}$ prolongamento do tempo transcorrido entre a semeadura e estabelecimento de plântulas no campo eleva os riscos referentes à ocorrência de danos de origem biótica e abiótica (Costa e Villela, 2006). O tratamento químico das sementes tem por objetivo o controle de organismos associados a estas e a sua proteção e das plântulas contra organismos do solo, contribuindo para a redução da transmissão de patógenos para a parte aérea das plantas (Lasca, 1986). Assim, tratamentos eficientes concorrem para redução do inóculo inicial no desenvolvimento de epidemias no campo (Menten, 1991). Alguns fungos de solo podem causar danos diretos ao estabelecimento do estande ocasionando o tombamento das plantas. Dentre as práticas recomendadas para o controle do tombamento, o tratamento das sementes com fungicidas tem se mostrado a principal medida adotada e a opção mais econômica para minimizar os efeitos negativos dessa doença (Goulart, 2002; Davis et al, 1997). 
Segundo Nunes et al. (2000) o condicionamento de sementes de cebola sem a aplicação de fungicida estimulou o desenvolvimento de fungos nas sementes, o que reduziu a porcentagem de germinação. Isso pode ter ocorrido devido à exposição das sementes a condições de umidade e temperatura durante o condicionamento que torna-se fator favorável ao desenvolvimento de patógenos. No entanto, tratamentos que associaram o condicionamento osmótico das sementes ao tratamento com fungicida foram eficientes na manutenção da germinação da espécie. A limitação das pesquisas que avaliam o efeito do tratamento com fungicida nas sementes condicionadas refere-se ao possível efeito tóxico de alguns fungicidas e ainda, à escassez de produtos recomendados ao tratamento dessas sementes.

Objetivou-se avaliar o efeito do condicionamento osmótico e do tratamento com fungicidas na qualidade fisiológica de sementes de beterraba (Beta vulgaris L.).

\section{MATERIAL E MÉTODOS}

O experimento foi realizado no Laboratório de Análise de Sementes pertencente do Departamento de Fitotecnia da Universidade Federal de Viçosa foi conduzido utilizando-se um lote de sementes de Beterraba, cultivar Early Wonder Super Tall Top, tratadas com fungicida Thiram a $0,15 \%$. Inicialmente, foi feita a caracterização da qualidade fisiológica das sementes do lote. Para tanto, as sementes foram submetidas ao teste de germinação utilizando-se quatro subamostras com 50 sementes, semeadas sobre papel plissado e umedecido com água na proporção de 3:1 (água: peso do papel), em caixas gerbox e estas mantidas em germinador a $20^{\circ} \mathrm{C}$. Realizaram-se contagens no $4^{\circ}$ e $14^{\circ}$ dia após a montagem do teste, calculando-se a percentagem de plântulas normais (Brasil, 1992).

Após a caracterização da qualidade inicial do lote, as sementes foram submetidas aos seguintes tratamentos com fungicidas: MET (Metalaxil a 0,004\%), PROC (Procimidone a $0,1 \%$ ) e MET + PROC (Metalaxil a $0,004 \%$ + Procimidone a $0,1 \%$ ), aplicados por via seca. Em seguida, as sementes de cada tratamento foram submetidas ao condicionamento osmótico em solução de PEG 6000 a $-0,8 \mathrm{MPa}(251 \mathrm{~g} / \mathrm{L})$ preparada conforme sugestão de Villela et al. (1991), em $\mathrm{KNO}_{3} 0,34 \mathrm{M}$ por $24 \mathrm{~h}$ e $\mathrm{H}_{2} \mathrm{O}$ por $16 \mathrm{~h}$. Em caixa gerbox, 20 $\mathrm{g}$ de sementes foram distribuídas sobre três folhas de papel germitest umedecidas com cada solução condicionadora, sendo este volume suficiente para garantir o contato das sementes com a solução, sem, no entanto, restringir a respiração das mesmas. As caixas foram tampadas e mantidas em incubadora BOD a $20^{\circ} \mathrm{C}$. Sementes não condicionadas foram utilizadas como testemunhas. Estas foram tratadas apenas com fungicida thiram a $0,15 \%$.

Após o período de condicionamento osmótico, as sementes foram lavadas e postas para secar sobre folhas de papel toalha em ambiente de laboratório (temperatura de $20^{\circ} \mathrm{C}$ e UR de $40 \%$ ) até atingirem teor de água de $10,5 \%$. Após a secagem, as sementes foram submetidas aos seguintes testes para avaliação do potencial fisiológico: germinação - foram utilizadas quatro subamostras com 50 sementes, semeadas sobre papel plissado, umedecidas com água na proporção de 3:1 (água: peso do papel), em caixas gerbox que foram mantidas em germinador a $20^{\circ} \mathrm{C}$. As avaliações foram realizadas conforme Brasil (1992); germinação no $4^{\circ}$ e no $8^{\circ}$ dia - conduzido conjuntamente com o teste de germinação. Registraram-se o número de plântulas normais, no quarto e oitavo dia após a semeadura; porcentagem, índice de velocidade de emergência e velocidade de emergência de plântulas em substrato comercial - realizada em bandejas de isopor de 200 células preenchidas com substrato comercial $\left(\right.$ Plantmax $^{\circledR}$ ). Quatro subamostras de 30 sementes de cada tratamento foram semeadas, colocando-se uma semente por célula, a $0,5 \mathrm{~cm}$ de profundidade. Foram realizadas contagens diárias do número de plantas normais até o décimo quarto dia após o semeio. Calculou-se a percentagem de plântulas normais obtidas aos 14 dias após a semeadura, o IVE (Maguire, 1962) e a velocidade de emergência (dias), segundo Nakagawa (1999); índice de velocidade de emergência em solo - realizado em bandejas contendo solo de área de cultivo de hortaliças. Utilizaram-se quatro repetições para cada tratamento, sendo cada repetição composta por uma linha de $30 \mathrm{~cm}$ onde foram distribuídas 30 sementes a $0,5 \mathrm{~cm}$ de profundidade. Foram feitas contagens diárias do número de plântulas emergidas até o décimo quarto dia após o semeio, calculando-se o índice de velocidade de emergência conforme descrito por Maguire (1962). Determinou-se ainda a percentagem de emergência de plântulas no décimo dia. Índice de emergência e porcentagem de tombamento de plântulas em solo - realizado conjuntamente com o índice de velocidade de emergência em solo. O índice de emergência (IES) foi obtido pela relação entre o número de plântulas emergidas e o número de glomérulos semeados e a percentagem de tombamento pela relação entre o número de plântulas tombadas e emergidas.

Os experimentos foram conduzidos em delineamento inteiramente casualizado com quatro repetições. Os dados das características avaliadas foram submetidos à análise de 
variância em esquema fatorial $4 \times 4$ (quatro tratamentos de condicionamento osmótico e quatro tratamentos fungicidas). As médias foram comparadas pelo teste de Duncan a 5\% de probabilidade, utilizando o software estatístico SAEG (2007).

\section{RESULTADOS E DISCUSSÃO}

Na Tabela 1 verifica-se que, em geral, o condicionamento osmótico não promoveu acréscimo significativo na germinação das sementes, exceto quando estas foram tratadas com metalaxil e condicionadas em $\mathrm{H}_{2} \mathrm{O}$ por $16 \mathrm{~h}$, as quais atingiram $90 \%$ de germinação, enquanto as sementes da testemunha não condicionada apresentaram $74 \%$ de germinação. Resultados semelhantes foram obtidos no quarto e oitavo dias. Ao se comparar os diferentes tratamentos fungicidas, observa-se que para as sementes da testemunha não condicionada não houve diferença entre os produtos utilizados, sendo que para sementes condicionadas em $\mathrm{H}_{2} \mathrm{O}$ por $16 \mathrm{~h}$ tiveram maior germinação quando tratadas com metalaxil, conforme já comentado. A mistura de fungicidas Met + Proc foi eficiente para aumentar a germinação das sementes condicionadas em $\mathrm{KNO}_{3}$ por $24 \mathrm{~h}$ e PEG por $24 \mathrm{~h}$ em relação aos demais tratamentos fungicidas. A avaliação da germinação no início do processo de germinação pode ser utilizada como um indicativo do vigor das sementes, estando relacionado à velocidade de germinação (Nakagawa, 1999).

TABELA 1. Germinação (\%) final, primeira contagem (quarto dia) e contagem no oitavo dia de sementes de beterraba (Beta vulgaris L.) submetidas ao condicionamento osmótico e tratamentos fungicidas.

\begin{tabular}{|c|c|c|c|c|}
\hline Tratamentos & Testemunha & Metalaxil (Met) & Procimidone (Proc) & Met+Proc \\
\hline \multicolumn{5}{|c|}{ Germinação final (\%) CV = 8,23\% } \\
\hline Testemunha & $75,50 \mathrm{Aa}^{*}$ & $73,50 \mathrm{Ab}$ & $78,50 \mathrm{Aa}$ & $77,30 \mathrm{Aab}$ \\
\hline $\mathrm{H}_{2} \mathrm{O} / 16 \mathrm{~h}$ & $80,50 \mathrm{Ba}$ & $90,00 \mathrm{Aa}$ & $78,00 \mathrm{Ba}$ & $76,50 \mathrm{Bb}$ \\
\hline $\mathrm{KNO}_{3} / 24 \mathrm{~h}$ & $57,00 \mathrm{Bb}$ & $66,00 \mathrm{Bb}$ & $64,50 \mathrm{Bb}$ & $78,00 \mathrm{Aab}$ \\
\hline PEG/24h & $74,00 \mathrm{Ba}$ & $74,00 \mathrm{Bb}$ & $73,50 \mathrm{Ba}$ & $86,50 \mathrm{Aa}$ \\
\hline \multicolumn{5}{|c|}{ Germinação (\%) quarto dia do teste de germinação $C V=15,85 \%$} \\
\hline Testemunha & $49,00 \mathrm{Aa}$ & 47,00 Aab & $49,00 \mathrm{Aa}$ & $49,50 \mathrm{Aa}$ \\
\hline $\mathrm{H}_{2} \mathrm{O} / 16 \mathrm{~h}$ & $48,50 \mathrm{Aa}$ & $54,50 \mathrm{Aa}$ & $47,00 \mathrm{Aa}$ & $52,50 \mathrm{Aa}$ \\
\hline $\mathrm{KNO}_{3} / 24 \mathrm{~h}$ & $49,50 \mathrm{ABa}$ & $43,25 \mathrm{Bb}$ & $30,50 \mathrm{Bb}$ & $53,50 \mathrm{Aa}$ \\
\hline PEG/24h & $25,50 \mathrm{Ab}$ & $30,00 \mathrm{Ac}$ & $21,00 \mathrm{Ac}$ & $24,00 \mathrm{Ab}$ \\
\hline \multicolumn{5}{|c|}{ Germinação (\%) no oitavo dia do teste de germinação (\%) CV =13,26\% } \\
\hline Testemunha & $70,50 \mathrm{Aa}$ & $74,00 \mathrm{Aab}$ & $68,00 \mathrm{Aa}$ & $73,00 \mathrm{Aa}$ \\
\hline $\mathrm{H}_{2} \mathrm{O} / 16 \mathrm{~h}$ & $63,00 \mathrm{Ba}$ & $86,50 \mathrm{Aa}$ & $75,50 \mathrm{Aba}$ & $74,00 \mathrm{ABa}$ \\
\hline $\mathrm{KNO}_{3} / 24 \mathrm{~h}$ & $67,50 \mathrm{ABa}$ & $62,50 \mathrm{ABb}$ & $54,50 \mathrm{Bb}$ & $74,50 \mathrm{Aa}$ \\
\hline $\mathrm{PEG} / 24 \mathrm{~h}$ & $62,00 \mathrm{Aa}$ & $62,00 \mathrm{Ab}$ & 67,75 Aab & $44,50 \mathrm{Bb}$ \\
\hline
\end{tabular}

* Para cada característica avaliada, médias dos tratamentos seguidas pela mesma letra minúscula na coluna e maiúscula na linha, não diferem entre si pelo teste Duncan a $5 \%$ de probabilidade.

A Tabela 2 apresenta os resultados relativos à emergência das plântulas de beterraba. Para as sementes não condicionadas, o tratamento com metalaxil aumentou a velocidade de emergência em substrato comercial em relação às sementes tratadas com a mistura Met + Proc. Já para as sementes condicionadas em água e $\mathrm{KNO}_{3}$ não houve diferença entre os fungicidas aplicados. Por outro lado, o tratamento das sementes com PEG associado ao fungicida metalaxil ocasionou germinação mais lenta (2,09 dias) em relação aos demais fungicidas. 
TABELA 2. Vigor de sementes de beterraba (Beta vulgaris L.) submetidas ao condicionamento osmótico e tratamentos fungicidas, avaliado por meio da velocidade de emergência em substrato comercial e em solo (IVE) e da emergência final (\%) em substrato comercial.

\begin{tabular}{lcccc}
\hline Tratamentos & Testemunha & Metalaxil (Met) & Procimidone (Proc) & Met+Proc \\
\hline \multicolumn{4}{l}{} \\
\hline Testemunha & $1,83 \mathrm{Aba}^{*}$ & $1,68 \mathrm{Bb}$ & $1,94 \mathrm{Aba}$ & $2,08 \mathrm{Aa}$ \\
$\mathrm{H}_{2} \mathrm{O} / 16 \mathrm{~h}$ & $1,83 \mathrm{Aa}$ & $1,99 \mathrm{Aa}$ & $1,85 \mathrm{Aab}$ & $1,75 \mathrm{Ab}$ \\
$\mathrm{KNO}_{3} / 24 \mathrm{~h}$ & $1,89 \mathrm{Aa}$ & $1,84 \mathrm{Aab}$ & $1,62 \mathrm{Ab}$ & $1,86 \mathrm{Aab}$ \\
$\mathrm{PEG} / 24 \mathrm{~h}$ & $1,69 \mathrm{Ba}$ & $2,09 \mathrm{Aa}$ & $1,65 \mathrm{Bab}$ & $1,79 \mathrm{Bab}$ \\
\hline
\end{tabular}

Velocidade de emergência em solo $\mathrm{CV}=15,12 \%$

\begin{tabular}{lllll}
\hline Testemunha & $2,16 \mathrm{Bb}$ & $3,76 \mathrm{Aa}$ & $2,25 \mathrm{Bb}$ & $3,76 \mathrm{Ab}$ \\
$\mathrm{H}_{2} \mathrm{O} / 16 \mathrm{~h}$ & $2,81 \mathrm{Cab}$ & $3,82 \mathrm{Ba}$ & $3,41 \mathrm{BCa}$ & $4,90 \mathrm{Aa}$ \\
$\mathrm{KNO}_{3} / 24 \mathrm{~h}$ & $3,19 \mathrm{ABa}$ & $3,91 \mathrm{Aa}$ & $2,99 \mathrm{Bab}$ & $3,72 \mathrm{ABb}$ \\
$\mathrm{PEG} / 24 \mathrm{~h}$ & $2,88 \mathrm{Bab}$ & $4,18 \mathrm{Aa}$ & $2,83 \mathrm{Bab}$ & $3,25 \mathrm{Bb}$ \\
\hline
\end{tabular}

Emergência (\%) em substrato comercial (\%) $\mathrm{CV}=7,32 \%$

\begin{tabular}{lllll}
\hline Testemunha & $81,66 \mathrm{Aa}$ & $80,83 \mathrm{Ab}$ & $88,33 \mathrm{Aab}$ & $90,83 \mathrm{Aa}$ \\
$\mathrm{H}_{2} \mathrm{O} / 16 \mathrm{~h}$ & $90,83 \mathrm{Aa}$ & $96,67 \mathrm{Aa}$ & $93,33 \mathrm{Aa}$ & $90,83 \mathrm{Aa}$ \\
$\mathrm{KNO}_{3} / 24 \mathrm{~h}$ & $90,83 \mathrm{ABa}$ & $92,50 \mathrm{Aa}$ & $81,67 \mathrm{Bbc}$ & $90,00 \mathrm{ABa}$ \\
$\mathrm{PEG} / 24 \mathrm{~h}$ & $83,33 \mathrm{ABa}$ & $90,00 \mathrm{Aa}$ & $76,67 \mathrm{Bc}$ & $83,33 \mathrm{ABa}$ \\
\hline
\end{tabular}

* Para cada característica avaliada, médias dos tratamentos seguidas pela mesma letra minúscula na coluna e maiúscula na linha, não diferem entre si pelo teste Duncan a 5\% de probabilidade.

Verifica-se que nenhum dos tratamentos de condicionamento osmótico contribuiu para aumentar a velocidade de emergência das plântulas em solo. Quanto ao efeito dos fungicidas, observa-se que as sementes da testemunha não condicionada tiveram maior velocidade de emergência quando tratadas apenas com procimidone, o que também ocorreu para as sementes condicionadas em $\mathrm{H}_{2} \mathrm{O}$ por 16h. Em geral, para as sementes sem condicionamento o tratamento com metalaxil resultou em germinação mais lenta em relação aos demais fungicidas.

O condicionamento osmótico não promoveu a melhoria do vigor das sementes, sendo o vigor daquelas condicionadas em PEG, inferior aos das demais. Conforme Furutani et al. (1986), a utilização de solução de PEG a -1,1MPa, por 24 e 48 horas, a $10^{\circ} \mathrm{C}$, promoveu redução na germinação de sementes de cebola, que estaria relacionada a alta viscosidade da solução de PEG 6000, restringindo a entrada de oxigênio, induzindo à anaerobiose e conseqüente produção de etanol, tóxico à semente. Capron et al. (2000), avaliando o efeito do condicionamento osmótico em sementes de beterraba açucareira, verificou a redução drástica na germinação de sementes tratadas por maior período em solução de PEG8000 a -2,0 MPa. Estes resultados concordam com aqueles obtidos por Nunes et al. (2000) para sementes de cebola. Também os tratamentos fungicidas aplicados antes do condicionamento osmótico não melhoraram a velocidade de germinação em relação à testemunha, sendo que o uso de metalaxil e procimidone nas sementes condicionadas com $\mathrm{KNO}_{3}$ afetou negativamente esta característica.

O condicionamento osmótico e tratamento fungicida apresentaram interação nos parâmetros emergência e velocidade de emergência em substrato comercial, velocidade de emergência em solo e para primeira contagem, contagem no oitavo dia e contagem final pelo teste de germinação. Não houve diferença significativa entre os tratamentos de condicionamento osmótico para a emergência de plântulas em substrato comercial para as sementes da testemunha tratada apenas com thiran e para aquelas tratadas com Met 
+ Proc. Efeitos benéficos do condicionamento osmótico só foram constatados para as sementes tratadas com metalaxil, onde todos os tratamentos de condicionamento osmótico foram superiores à testemunha não condicionada.

Pelos resultados obtidos para velocidade de emergência de plântulas em substrato comercial (Tabela 2) verificase que não houve efeito benéfico do condicionamento para as sementes tratadas com thiran e metalaxil. Apenas nas sementes tratadas com Procimidone e Proc + Met o condicionamento favoreceu significativamente esta característica, especialmente o condicionamento em $\mathrm{KNO}_{3}$ e $\mathrm{H}_{2} \mathrm{O}$, respectivamente. Nota-se que este último também foi benéfico à germinação e primeira contagem. Estes resultados estão de acordo, em parte, com os obtidos por Costa e Villela (2006), onde o condicionamento osmótico, bem como a pré-hidratação em água não foram eficientes na melhoria da emergência das sementes de beterraba em casa de vegetação. Segundo Welbaum et al. (1998), embora o condicionamento osmótico de sementes seja indicado para o aumento na germinação e uniformização da emergência de plântulas, as respostas são variáveis entre as espécies, apresentando como um benefício, em geral, comum às mesmas, o aumento na velocidade e uniformidade na germinação e emergência de plântulas.

Houve efeito do condicionamento osmótico para índice de velocidade de emergência em substrato comercial e índice de emergência em solo (Tabela 3) e de tratamento fungicida para índice de velocidade de emergência em solo e percentagem de plântulas tombadas (Tabela 4).

TABELA 3. Efeito dos diferentes tratamentos de condicionamento osmótico em sementes de beterraba (Beta vulgaris L.) sobre o índice de velocidade de emergência em substrato comercial (IVESC) e índice de emergência em solo (IES).

\begin{tabular}{lcc}
\hline Condicionamento Osmótico & IVESC & IES \\
\hline Testemunha & $3,98 \mathrm{c}^{*}$ & $0,95 \mathrm{c}$ \\
$\mathrm{H}_{2} \mathrm{O} / 16 \mathrm{~h}$ & $4,89 \mathrm{a}$ & $1,38 \mathrm{a}$ \\
$\mathrm{KNO}_{3} / 24 \mathrm{~h}$ & $4,55 \mathrm{~b}$ & $1,31 \mathrm{a}$ \\
$\mathrm{PEG} / 24 \mathrm{~h}$ & $3,91 \mathrm{c}$ & $1,13 \mathrm{~b}$ \\
\hline $\mathrm{CV}(\%)$ & 8,88 & 15,61 \\
\hline
\end{tabular}

* Médias dos tratamentos, para cada característica, seguidas por uma mesma letra nas colunas, não diferem entre si pelo teste Duncan a $5 \%$ de probabilidade.
TABELA 4. Efeito do tratamento fungicida em sementes de beterraba (Beta vulgaris $L$.), sobre o índice de velocidade de emergência em solo (IVES) e sobre o percentual de plântulas tombadas em solo (PPTS).

\begin{tabular}{lcc}
\hline Tratamento Fungicida & IVES & PPTS (\%) \\
\hline Testemunha & $4,42 \mathrm{c}^{*}$ & $50,86 \mathrm{a}$ \\
Metalaxil & $6,02 \mathrm{a}$ & $7,47 \mathrm{~b}$ \\
Procimidone & $4,23 \mathrm{c}$ & $61,85 \mathrm{a}$ \\
Metalaxil + Procimidone & $5,16 \mathrm{~b}$ & $6,39 \mathrm{~b}$ \\
\hline CV $(\%)$ & 20,35 & 49,63 \\
\hline
\end{tabular}

* Médias dos tratamentos, para cada característica, seguidas por uma mesma letra nas colunas, não diferem entre si pelo teste Duncan a 5\% de probabilidade.

O condicionamento osmótico e o tratamento com fungicidas em sementes de beterraba, especialmente com o fungicida metalaxil, foram determinantes para o estabelecimento das plantas em condições de solo, incrementando o índice de velocidade de emergência em solo e reduzindo o percentual de plântulas tombadas no décimo quarto dia (Tabela 3). De acordo Nascimento (2005), um rápido estabelecimento da cultura em campo pode reduzir os prejuízos ocasionados pela ação de microrganismos, especialmente de fungos dos gêneros Pythium, Phytophthora, Rhizoctonia e Fusarium. Conforme Osburn e Schroth (1989) e Rush (1991), para beterraba, sementes condicionadas vem sendo utilizadas como técnica para minimizar o efeito desses microrganismos, reduzindo assim a incidência de damping off.

\section{CONCLUSÕES}

$\mathrm{O}$ condicionamento em água por $16 \mathrm{~h}$ associado ao tratamento das sementes com o fungicida metalaxil $(0,004 \%)$, aumenta a germinação e a emergência de plântulas de beterraba em substrato comercial e reduz o tombamento de plântulas em campo.

\section{REFERÊNCIAS}

BEWLEY, J.D.; BLACK, M. Seeds: physiology of development and germination. 2.ed. New York: Plenum Press, 1994. 445p.

BRASIL. Ministério da Agricultura e Reforma Agrária. Regras para análise de sementes. Brasília, DF: SNDA/ 
DNDV/CLAV, 1992. $365 \mathrm{p}$.

CAPRON, I.; CORBINEAU, F.; DACHER, F.; JOB, C.; COME, D.; JOB, D. Sugarbeet seed priming: effects of priming conditions on germination, solubilization of 11-S globulin and accumulation of LEA proteins. Seed Science Research. v. 10, n. 3, p. 243-254, 2000.

CARVALHO, N.M.; NAKAGAWA, J. Sementes: ciências, tecnologia e produção. 4.ed. Jabotical: FUNEP, 2000. 565p.

COSTA, C.J.; VILLELA, F.A. Condicionamento osmótico de sementes de beterraba. Revista Brasileira de Sementes, v. 28, n.1, p. 21-29, 2006

DAVIS, R.M., NUNEZ, J.J.; SUBBARAO, K.V. Benefits of cotton seed treatments for the control of seedling diseases in relation to inoculum densities of Pythium species and Rhizoctonia solani. Plant Disease, v. 81, n.7, p. 766-768, 1997.

HAIGH, A.M.; BARLOW, E.W.R.; MILTHORPE, F.L.; SINCLAIR, P.J. Field emergence of tomato, carrot and onion seeds primed in aerated salt solution. Journal of Amercian Society of Horticultural Sciences, v.111, p.660-665, 1986.

FURUTANI, S.C.; ZANDSTRA, B.H. \& PRICE, H.C. The effects of osmotic solute composition and duration and temperature of priming on onion seed germination. Seed Science and Technology, v.14, n.3, p.545-551, 1986.

GOULART, A.C.P. Efeito do tratamento de sementes de algodão com fungicidas no controle do tombamento de plântulas causado por Rhizoctonia solani. Fitopatologia Brasileira, v.27, n.4, p. 399-402. 2002.

KHAN, A.A.; PECK, N.H.; TAYLOR, A.G.; SAMIMY, C. Osmoconditioning of beet seeds to improve emergence and yield in cold soil. Agronomy Journal, v. 75, p. 788-794, 1983.

LASCA C. Tratamento de sementes. In: SIMPÓSIO BRASILEIRO DE PATOLOGIA DE SEMENTES, 2., 1986, Campinas. Palestras... Campinas: Fundação Cargill, 1986. p. $92-99$

MAGUIRE, J.D. Speed of germination-aid in selection and evaluation for seeding emergence and vigor. Crop Science, v.2, n.2, p.176-177, 1962.

MENTEN J. Patógenos em sementes: detecção, danos e controle químico. Piracicaba: FEALQ, 1991. 321p.

NAKAGAWA, J. Testes de vigor baseados no desempenho das plântulas. In: KRZYZANOWSKI, F.C.; VIEIRA, R.D.; FRANÇA NETO, J.B. (Ed.). Vigor de sementes: conceitos e testes. Londrina: ABRATES, 1999. ca. 2, p. 1-24.

NASCIMENTO, W.M. Condicionamento osmótico de sementes de hortaliças. Brasília,DF: Embrapa Hortaliças, 2004. 12p. (Embrapa Hortaliças. Circular Técnica, 33).

NASCIMENTO, W.M. Condicionamento osmótico de sementes de hortaliças visando a germinação em condições de temperaturas baixas. Horticultura Brasileira, v.23, n.2, p.211-214, 2005.

NUNES, U.R.; SANTOS, M.R.; ALVARENGA, E.M.; DIAS, D.C.F.S. Efeito do condicionamento osmótico e do tratamento com fungicida na qualidade fisiológica e sanitária de sementes de cebola (Allium cepa L.). Revista Brasileira de Sementes, v.22, n.1, p. 239-246, 2000.

OSBURN, R.M.; SCHROTH, M.N. Effect of osmopriming sugar beet seed on germination rate and incidence of Pythium ultimum damping-off. Plant Disease, v.73, p.21-24, 1989.

PUIATTI, M.; FINGER, F. L. Cultura da beterraba. In.: FONTES, P. C. R. Olericultura: teoria e prática. Viçosa: Editora Suprema, 2005. 486 p.

RUSH, C.M. Comparison of seed priming techniques with regard to seedling emergence and Pythium damping-off in sugar beet. Phytopathology, v.81, n.8, p.878-882, 1991.

SAEG. Sistema para análises estatísticas. Viçosa: UFV: Fundação Arthur Bernardes, 2007. V Versão 9.1

SILVA, J.B.; VIEIRA, R.D. Avaliação do potencial fisiológico de sementes de beterraba. Revista Brasileira de Sementes, v.28, n.2, p. 128-134, 2006.

TONIN, G. A.; GATTI, A. B.; CARELLI, B. P.; PEREZ, S. C. J. G. A. Influência da temperatura de condicionamento osmótico na viabilidade e no vigor de sementes de Pterogyne nitens Tull. Revista Brasileira de Sementes, v. 27, n. 2, p.35-43, 2005.

VILLELA, F.A.; DONI FILHO, L.; SEQUEIRA, E.L. Tabela de potencial osmótico em função da concentração de polietilenoglicol 6.000 e da temperatura. Pesquisa Agropecuária Brasileira, Brasília, DF, v. 26, n. 11/12, p. 1957-1968, 1991.

WELBAUM, G.E.; SHEN, Z.; OLUOCH, M.O.; JETT, L. The evolution and effects of priming vegetable seeds. Seed Technology, v. 20, n. 2, p.209-235, 1998.

YEOUNG, Y.R.; WILSON, D.O. Effects of oxygen concentrations on germination during onion and sugar beet seed priming. Journal of the Korean Society for Horticultural Science, v. 36, n. 5, p. 628-634, 1995. 